\title{
Simultanmethode für die Bestimmung von Kupfer und Eisen im Serum
}

\author{
Von R. Kattermann und B. Köhring \\ Sektion Klinische Chemie, Medizinische Universitätsklinik Göttingen
}

(Eingegangen am 8. April 1971)

\begin{abstract}
Die Analyse von Kupfer und Eisen im Serum wird in den meisten Laboratorien als manuelle, photometrische Bestimmung durchgeführt. Wegen der in der Klinik häufigen gemeinsamen Anforderungen beider Parameter wird in der vorliegenden Arbeit eine Simultanbestimmung von Kupfer und Eisen aus einer Probe mit einem Standard-2-Kanal-Auto-Analyzer vorgeschlagen.

Nach unseren Erfahrungen weist dieses Verfahren gegenüber der manuellen Methodik folgende Vorteile auf: Einfache Durchführung mit selbst herstellbaren Reagenzien, Probenausstoß von je 30-35 Analysen/Std., geringe Störanfälligkeit gegenüber hämolytischen, ikterischen oder lipämischen Seren durch Verwendung der Dialyse, größtmögliche Sicherheit vor groben Fehlern in Form von kontaminierten Pipetten, Zentrifugenröhrchen, Reagenzgläsern und Küvetten.

Die Brauchbarkeit der Methode wurde während 6 Monaten eingehend geprüft: Bei hoher Spezifität und ausreichender Empfindlichkeit ergab sich für die Kupferbestimmung eine Wiederholbarkeit von 2,8\% (VK) und cine Wiederfindung von $99,7 \%$. Die Präzision lag für Kupfer bei 5-6\%, für Eisen bei 9-10\%, während die Richtigkeit für beide Parameter nur um 1-2\% von den empfohlenen Werten eines Kontrollserums abwich. Demnach kann die beschriebene Methode für den Einsatz im klinisch-chemischen Laboratorium vorbehaltlos empfohlen werden.
\end{abstract}

\section{$A$ method for the simultaneous determination of copper and iron in serum}

In most laboratories, copper and iron are determined in serum by a manual photometric method. Since the clinical laboratory is often asked for both of these parameters together, the present work describes the simultaneous measurement of copper and iron in one sample with a standard 2-channel Auto-Analyser.

This procedure has the following advantages over the manual method: simple operation with reagents that can be prepared in the laboratory; 30-35 analyses per hour; the use of dialysis results in low interference by haemolytic, icteric or lipaemic sera; avoidance of crude errors that may result from contaminated pipettes, centrifuge tubes, test tubes and curettes.

The suitability of the method was tested thoroughly for a period of six months. The method is highly specific and the sensitivity is adequate. The determination of copper gave a repeatability of $2.8 \%$ (var. coeff.) and a recovery of $99.7 \%$. The precision was $5-6 \%$ for copper and $9-10 \%$ for iron, while the measured values of both parameters varied by only $1-2 \%$ from the true values of a control serum. The method is therefore unreservedly recommended for use in the clinical chemical laboratory.

Die Bestimmung von Kupfer und Eisen im Serum ist für die Klinik von Interesse nicht nur im Rahmen gezielter, differentialdiagnostischer Fragestellungen $(1,2)$, sondern auch als Suchtest für den Nachweis entzündlicher bzw. maligner Organ- oder Systemerkrankungen $(3,4,5)$. Daher fallen in den meisten Kliniklaboratorien große Zahlen von Kupfer- und Eisenbestimmungen an. Der Zeitaufwand für die Durchführung dieser Bestimmungen ist relativ hoch, zumindest wenn mit einem Enteiweißungsschritt gearbeitet wird. Außerdem gilt die Analyse von Kupfer und Eisen im Serum als störanfällig, eine Erfahrungstatsache, die durch die Ergebnisse der kürzlich durchgeführten Ringversuche $(6,7)$ mit exakten Zahlen belegt worden ist.

Im folgenden möchten wir eine Simultanbestimmung von Kupfer und Eisen unter Verwendung eines Standard-Auto-Analyzers (2-Kanal-Gerät) beschreiben. Diese Methode weist gegenüber den manuellen Verfahren zahlreiche, prinzipielle Vorteile auf, erlaubt einen effektiven Ausstoß von je 30-35 Proben/Std. und ergibt bei der Untersuchung von Präzision und Richtigkeit befriedigendere Resultate als die manuelle Methode.

\section{Methodik}

Der Simultanbestimmung liegen folgende Prinzipien zugrunde: Kupfer - nach Summers (8).

Das im Serum hauptsächlich an Coeruloplasmin gebundene Kupfer wird mit $1 \mathrm{~N} \mathrm{HCl}$ abgespalten, bei $37^{\circ}$ gegen 0,9 proz.
$\mathrm{NaCl}$ dialysiert und mit einem Reagenz aus Oxalyldihydrazid, Acetaldehyd und Ammoniak zu einem violetten Farbkomplex umgesetzt, dessen Extinktion bei $550 \mathrm{~nm}$ gemessen wird.

\section{Herstellung der Reagenzien}

1N Salzsäure: $130 \mathrm{ml} 25$ proz. $\mathrm{HCl}$ p. a. in einem 1-Liter-Meßkolben mit $600 \mathrm{ml}$ bidest. Wasser mischen und nach dem $\mathrm{Ab}$ kühlen auf $1000 \mathrm{ml}$ auffüllen.

Physiol. NaCl-Lösung: $18 \mathrm{~g} \mathrm{NaCl}$ p. a. in $2000 \mathrm{ml}$ bidest. Wasser lösen und $1 \mathrm{ml}$ Brij-35 zusetzen.

Farbreagens für Kupfer: 1,0 g Oxalyldihydrazid p. a. (Fa. Serva, Heidelberg) unter Rühren im Meßkolben in $1000 \mathrm{ml}$ bidest. Wasser lösen, im Kühlschrank aufbewahren. Zu $500 \mathrm{ml}$ der kalten Lösung $50 \mathrm{ml}$ 25proz. Ammoniak p. a. und schließlich $15 \mathrm{ml}$ vorgekühlten Acetaldehyds p. a. zusetzen. Das Reagenz ist unter Verschluß im Kühlschrank mehrere Tage haltbar.

Eisen - nach ZaK und EpSTEIN (9).

Das an Transferrin gebundene Serumeisen wird in $1 \mathrm{~N} \mathrm{HCl}$ abgespalten und gleichzeitig mit Ascorbinsäure reduziert. Das zweiwertige Eisen dialysiert gegen einen 1M Acetatpuffer $(\mathrm{pH} 4,65)$ und bildet dann mit Bathophenanthrolinsulfonat einen toten Farbkomplex, dessen Extinktion bei $550 \mathrm{~nm}$ gemessen wird.

\section{Herstellung der Reagenzien}

Ascorbinsäure- $\mathrm{HCl}: 5,0 \mathrm{~g}$ Ascorbinsäure p. a. wcrden in $50.0 \mathrm{ml}$ 1N $\mathrm{HCl}$ gelöst und $0,25 \mathrm{ml}$ Brij-35 zugesetzt. Im Kühlschrank aufbewahren!

1M Acetatpuffer $\mathrm{pH}$ 4,65: $136 \mathrm{~g} \mathrm{Na}$-Acctat $3 \mathrm{H}_{2} \mathrm{O}$ in $1500 \mathrm{ml}$ bidest. Wasser löscn, dann $60 \mathrm{ml} 96 \mathrm{proz}$. Essigsäure zugeben und auf $2000 \mathrm{ml}$ mit bidest. Wasser auffüllen. Zusatz von $1,0 \mathrm{ml} \mathrm{Brij-}$ 35. 
Farbreagenz für Eisen (Bathophenanthrolinsulfonsäure $200 \mathrm{mg} / \mathrm{l}$ ): $100 \mathrm{mg}$ Bathophenanthrolinsulfonsäure in $500 \mathrm{ml}$ bidest. Wasser lösen. Mindestens 1 Monat im Kühlschrank haltbar.

\section{Herstellung von Misch-Standards}

Zunächst Stammlösungen mit jeweils $100 \mathrm{mg} / \mathrm{l} \mathrm{Cu}++$ bzw. $\mathrm{Fe}^{++}$ ansetzen: $98,25 \mathrm{mg}$ Kupfer-II-sulfat $\cdot 5 \mathrm{H}_{2} \mathrm{O}$ in bidest. Wasser ad $250 \mathrm{ml}$ lösen. $175 \mathrm{mg}$ Eisen-II-Ammoniumsulfat $\cdot 6 \mathrm{H}_{2} \mathrm{O}$ in etwas bidest. Wasser lösen, $2,5 \mathrm{ml}$ 25proz. $\mathrm{HCl}$ zusetzen und mit Wasser ad $250 \mathrm{ml}$ auffüllen.

\section{Gebraucbsstandards}

Durch Einpipettieren von $1,0-2,0-3,0-4,0-5,0$ und $10,0 \mathrm{ml}$ der beiden Stammlösungen in sorgfältig gespülte $200 \mathrm{ml}$ Meßkolben erhält man nach Auffüllen mit bidest. Wasser die entsprechenden wäßr. Standards mit Kupfer und Eisenkonzentrationen von 0,5 bis $5 \mathrm{mg} / \mathrm{l}$. Die für beide Verfahren verwendeten Reagenzien waren sämtlich - soweit nicht anders angegeben Handelspräparate der Firma Merck A. G., Darmstadt.

\section{Praktiscbe Durchfïbrung (s. Abb. 1)}

Bei Verwendung eines 2-Kanal-Auto-Analyzers ohne besonderes Zubehör werden für die Methode mindestens $3 \mathrm{ml}$ Serum oder Plasma benötigt. Bei Verwendung eines Spezial-Kolorimeters mit $50 \mathrm{~mm}$ Lichtweg steigt die gemessene Extinktion entsprechend an, so daß man dann auch mit einem normalen Probenbecher und einer Serummenge von etwa $1 \mathrm{ml}$ arbeiten kann. In vielen Kliniken wird für die Kupfer-EisenBestimmung òhinehin ein separates Röhrchen abgenommen. Nach dem Zentrifugieren wird das überstehende Serum sofort in einen großen Probenbecher (z. B. Nr. 127061 von Technicon oder 38/14 von Sarstedt) abgegossen und zugedeckelt. Nach Einstellen der Reagenziengrundlinien werden zunächst die wäßrigẹn Eichstandards, dann ein Kontrollserum und die Proben analysiert. Auf dem Probenteller werden nach jeder 10. Probe zwei Gefäße mit bidest. Wasser eingeschoben. Die Einzelheiten des Fließschemas sind aus Abbildung 1 ersichtlich:

Verteilung der Probe auf die beiden Kanäle mittels eines $A_{11^{-}}$ Fitting, Verbindung zwischen Manifold, Dialyse, Ölbad und Kolorimetern mit normalem Tygon-Leitungsschlauch.

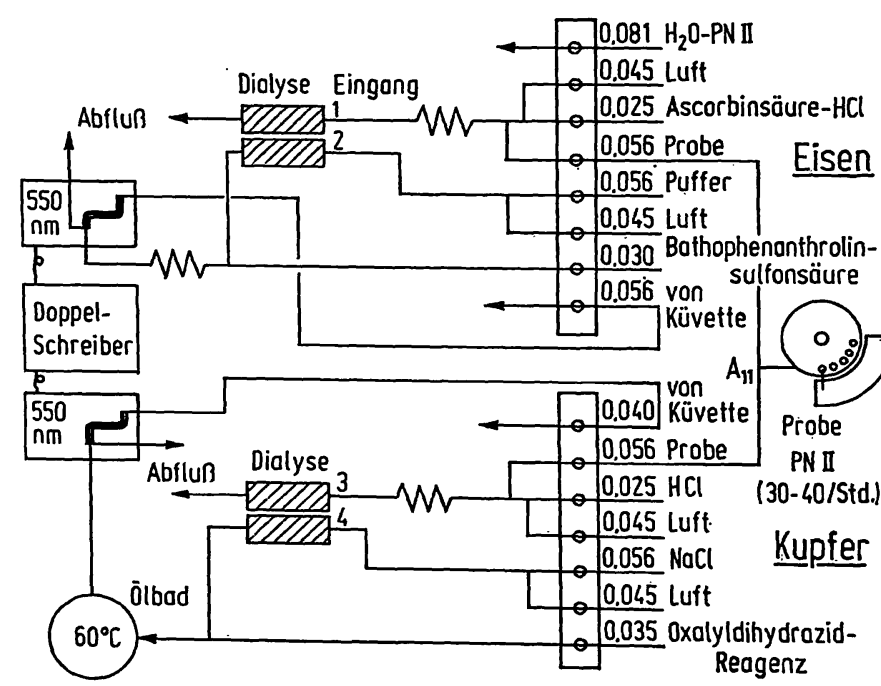

Abb. 1

Fließschema für die Simultanbestimmung von Kupfer und Eisen im Serum unter Verwendung eines Zweikanal-Auto-Analyzers (Proben-
nehmer II, Proportionierpumpe II, Doppeldialysator, Oibad mit ver-
stellbarem Kontaktthermometer stellbarem Kontaktthermometer, 2 Kolorimeter mit Durchflußküvette $15 \mathrm{~mm}$ und Zweikanal-Linienschreiber).

Pumpen- und Leitungsschläuche aus Tygon. Mischspiralen: Doppelmischschlangen Technicon-Nr. MSC 2 Nockenscheibe am Probennehmer II entweder 40-2/1 oder 30-2/1. In letzterem Fall empfiehlt sich eine Änderung des Probe-Wasch-Verhältnisses auf 1,75/1,25. Mit einer solchen "Spezial-Nockenscheibe" wurden die in Abb. 4 gezeigten Kurven geschrieben
Bei Verwendung einer Proportionierpumpe II lassen sich die beiden Schlauchsysteme auf einer Manifold-Platte unterbringen. Es ist vorteilhaft, den Probennehmer mit einer Frequenz von 30/Std. bei einem etwas veränderten Probe-Wasch-Verhältnis laufen zu lassen. Aber auch mit einer 40 er-Nockenscheibe $(2: 1)$ werden gut getrennte ,peaks" und reproduzierbare Kurven geschrieben. Generell ist hervorzuheben, $\mathrm{da} \beta$ die oft umständlichen und im Labor unbeliebten, speziellen Reinigungsverfahren für die bei der Kupfer-Eisen-Analyse benötigten Glasgeräte für die beschriebene Methodik vollständig entfallen.

\section{Ergebnisse}

Reaktionsbedingungen für die Kupferbestimmung

Nach einer Reihe von Vorversuchen mit Oxalyldihydrazid, Bathocuproin, Cuprizon und Diphenylcarbazid wählten wir die erstere Verbindung für weitere Versuche aus, da der gebildete Kupfer-Komplex im wäßrigen Milieu relativ beständig ist, ein gut meßbares Extinktionsmaximum bei $540 \mathrm{~nm}$ aufweist und die Farbbildung dem LAMBERT-BEER'schen Gesetz folgt. Im Gegensatz zum Diphenylcarbazid ist der $\mathrm{pH}$-Wert bei der Komplexbildung nicht kritisch: Nach unseren Untersuchungen erhält man ein plateauförmiges $\mathrm{pH}-\mathrm{Optimum}$ zwischen $\mathrm{pH} 9$ und 10, so daß kleinere $\mathrm{pH}-S c h w a n k u n g e n$ in diesem Bereich nicht stören. Der Zusatz einer in diesem Bereich puffernden Substanz hatte keinen Effekt auf die

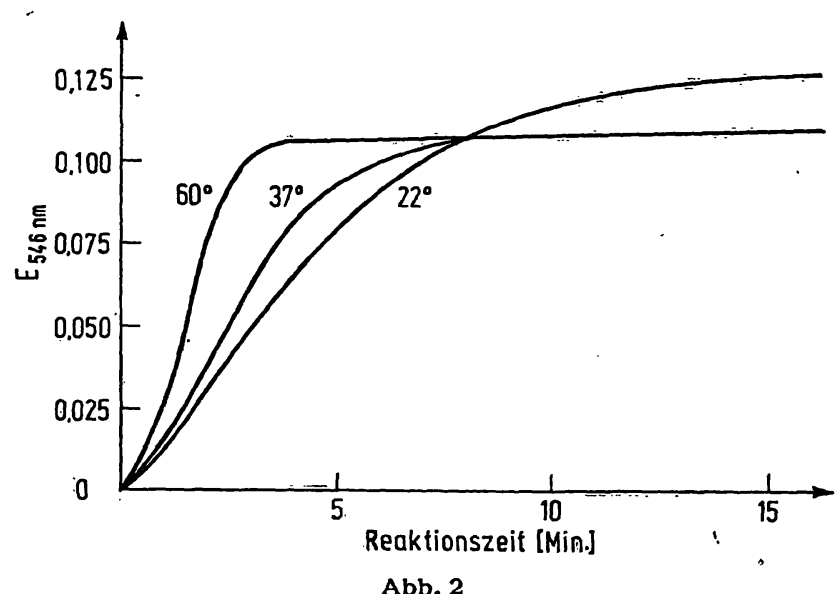

Farbreaktion von Kupfer mit Oxalyldihydrazid-Acetaldehyd-Ammoniak in Abhängigkeit von der Temperatur.

Ansaugen eines wäßr. Kupferstandards $(2,5 \mathrm{mg} / \mathrm{l})$ durch das in Abb. 1 angegebene AutoAnalyzer-System. Auffangen des Reaktionsgemisches in einem Reagenzglas nach Zugabe des Kupfer-Reagenz. Überführen in eine Normalküvette $10 \mathrm{~mm}$, Messung der Extinktionszunahme bè $546 \mathrm{~nm}$ am Photometer Eppendorf mit temperierbarem Küvettenhalter unter Verwendung eines Kompensationsschreibers (Skalenspreizung $0-0,25)$. - Einzelheiten s. Methodik und Ergebnisse

Farbgebung; ausschlaggebend ist das Vorhandensein von Ammoniak für die Neutralisation, A.lkalisierung und Komplexbildung. In weiteren Versuchen wurden die optimalen Konzentrationen von Acetaldehyd (etwa $500 \mathrm{~mm}$ ) und Oxalyldihydrazid (etwa $2 \mathrm{~mm}$ ) sowie die für die Abspaltung des Kupfers nötigen Konzentrationen an Salzsäure $(1-2 \mathrm{~N})$ ermittelt. Außerdem bemühten wir uns, die Farbbildung in Abhängigkeit von Zeit und Inkubationstemperatur zu optimieren. Die Ergebnisse entsprechender Versuche sind in Abbildung 2 dargestellt. Bei Raumtemperaturen wird mit einem Kupfer- 


\section{Laborautomatisation - konsequent und zukunftssicher}

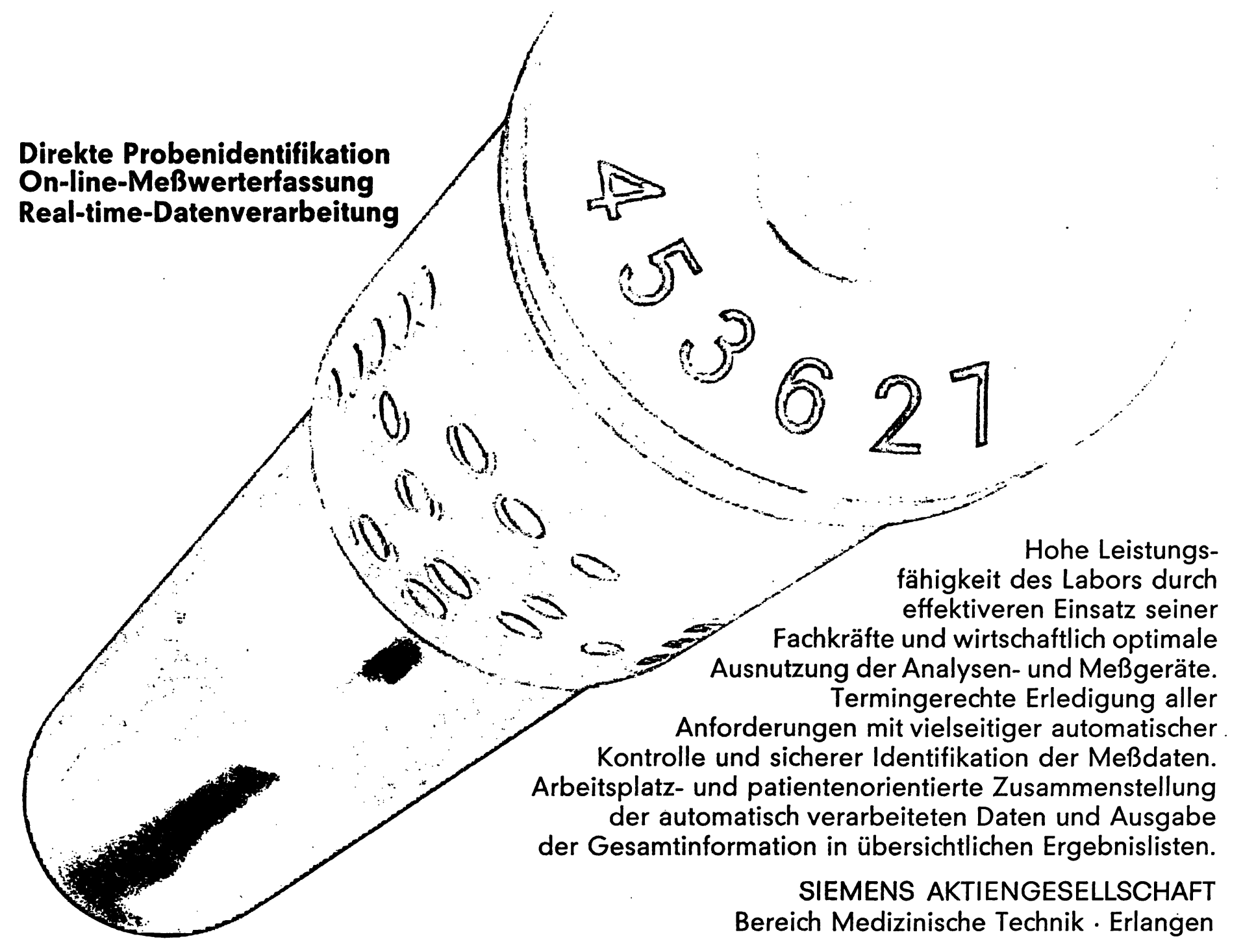

\section{mina dem SILAB-System yon Siemens}


Nicotinamid-Adenin-Dinucleotid B-Diphosphopyridin-Nucleotid (DPN)

Verbraucher großer Mengen NAD sind eingeladen, ihren Bedarf mit Sigma żu diskutieren. Als ältester Hersteller des besten NAD und NADH der Welt sind wir vortrefflich in der Lage zur Kooperation. Mengen von vielen Kilogramm können unmittelbar von unserem umfangreichen Lager verfrachteł werden.

Preise: Können für unabgepackte Mengen sowohl für Auto-Analyzer- als auch Forschungsqualitäten vereinbart werden. Reinheit: Wir bieten verschiedene Reinheitsgrade an, um Ihrer Zufriedenheit zu genügen.

\section{Qualität V}

Diese ist ein in kleinen Partien nachgereinigtes NAD unserer bekannten Qualität III. Geringe Verunreinigungen wurden vermindert, um das „enzyme lag“ zu eliminieren.

Literatur: 1. Dalziel, K., J. biol. Chemistry 238, 1538 (1963)

2. Winer, A. D., J. biol. Chemistry 239, PC 3598 (1964)

\section{Qualität III}

Unsere weltberühmte „Arbeitspferd“-Qualität: das vermutlich weltweit anerkannte NAD sowohl für Forschung als auch klinische Untersuchungen. Empfohlen, wo fast maximale Präzision wichtig ist.

\section{Qualität AA}

Eine spezielle Qualität, hergestellt für Anwendungen, die nicht die höchste Reinheit erfordern. Obwohl sie nicht unserer Qualität III entspricht, ist sie garantiert mindestens so rein wie jedes billigere NAD, das gegenwärtig für den Gebrauch in automatischen Analyzern zur Verfügung steht. Dennoch ist der Preis für unabgepackte Mengen von $100 \mathrm{~g}$ und mehr bedeutend geringer als er für unsere Qualität III möglich ist.

Wenn Sie einen wesentlichen Bedarf an NAD (DPN) haben, rufen Sie mich bitte zu jeder Tages-oder Nachtzeit und voe überall her in der Welt „,von Person zu Person" (selbstverständlich R-Gespräch) an. Ich denke, es könnte sich für Sin lohnen.

Danke Dan Broida Mein Fernruf: 314-993-6418

Es ist ein Vergnügen, Geschäfte mit Sigma zu machen

Bestellen Sie direkt - R-Gespräch von überall her in der Welt

Tagsüber von Haus zu Haus, 314-771-5750 (auch Samstag und Sonntag bis 13.00 Uhr)

Wenn Sie mit Dan Broida persönlich sprechen möchten, rufen Sie „von Person zu Person“ 314-993-6418 Tag und Nacht.

Sigma-Reagenzien sind in der ganzen Welt durch den Fachhandel oder direkt aus St. Louis beziehbar.

Telegramme: SIGMACHEM, St. Louis, Missouri

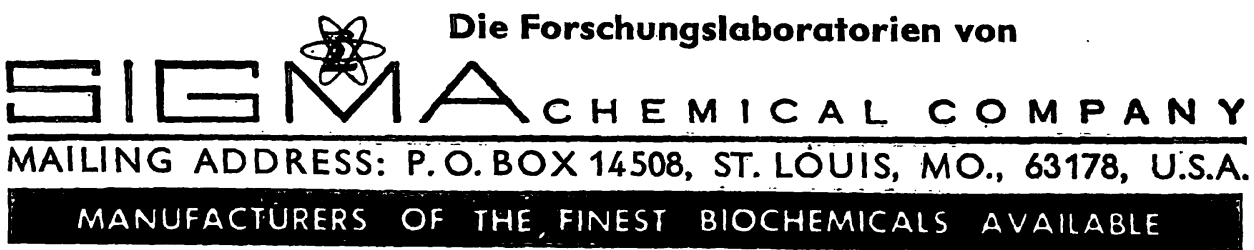

Vertreten durch

SIGMA LONDON Chem. Co. Ltd. 12, Lettice St., Londọ, S. W. 6., England Telephone: 01-736-5823 (Reverse Charges)

SIGMA ISRAEL Chem. Co. Ltd. 28 Kaf-Gimel St., Givataim, Israel Telephone: (03) 760654 (Reverse Chargès) 
standard von $2,5 \mathrm{mg} / 1$ die maximale Extinktion erst nach ctwa 15 Min. errcicht. Durch Erhöhung der Rcaktionstemperatur auf $37 \mathrm{bzw} .60^{\circ}$ registriert man dieses Maximum bereits nach 10 bzw. 5 Min., was die Verwendung von Verzögcrungsschlangen erspart.

\section{Spczifität und Empfindlichkeit der Kupfer-} bestimmung

Von verschiedenen Salzen des Eisens, Zinks, Mangans, Calciums, Magnesiums und Lithiums wurden jeweils 2 wäßrige "Standards" in den Konzentrationen von 2,5 und $5 \mathrm{mg} / \mathrm{l}$ angesetzt. Diesc Lösungen wurden zusammen mit entsprechenden Kupferstandards im Auto-Analyzer zur Bestimmung gebracht. Keines der genannten Kationen außer Eisen entwickelte unter unseren Versuchsbedingungen cinc die Kupferbestimmung störende Farbc. Die Eisenlösungen ergaben eine bei 2,5\% des entsprechenden Kupferstandards liegende Extinktion. Der minimale, in unserem System noch mit Sicherheit ablesbare Kupfergchalt lag bci 0,2 mg/l. Derartige Konzentrationen zeigten gegenüber dem Leerwert einen Anstieg der $E_{650}$ um 0,01 bei einer Schichtdicke von $15 \mathrm{~mm}$.

Wiederfindung und Wiedcrholbarkeit der Kupferbestimmung (Tab. 1)

5 ml-Portionen eines pool-Serums, dessen Gchalt durch 10 fache Bestimmung genau ermittelt wurde, wurden

Tab. 1

Wicderfindung von Kupfer $(20 \mu$ l einer wäßr. Lösung von Kupfersulfat init $400 \mathrm{mg} / \mathrm{l} \mathrm{Cu}^{++}$) in bidest. Wasser bzw. pool-Serum bel Bestimmung mittels Oxalyldihydrazld am AutoAnalyzer.

Die IViederholbarkeit ("Präzision in der Serie") liegt mit den Variationskoeffizienten (VK) von $2-4 \%$ deutlich niedriger als bei der Präzision der Kupferbestimnung "von Tag zu Tag" (s. Tabelle 2)

\begin{tabular}{|c|c|c|c|}
\hline & pool-Serum & $\begin{array}{l}\text { Bidest. } \\
\text { Wasser } \\
+ \text { Kupfer- } \\
\text { zusatz }\end{array}$ & $\begin{array}{l}\text { pool-Serum } \\
+\underset{\text { Kusatz }}{\text { Kupfer- }}\end{array}$ \\
\hline $\begin{array}{l}\text { Anzahl der Bestimmungen } \\
\text { Mittelwert } \bar{x} \text { (in mg/l) } \\
\text { Standardabweichung } s \bar{x} \\
\text { Variations-Koeffizient (VK) } \\
\text { Wiederfindung (in } \% \text { ) }\end{array}$ & $\begin{array}{l}10 \\
1,62 \\
0,063 \\
3,9 \% \\
\varnothing\end{array}$ & $\begin{array}{r}4 \\
1,61 \\
0.025 \\
1,6 \% \\
+0,7 \%\end{array}$ & $\begin{array}{l}30 \\
3,22 \\
0,089 \\
2,8 \% \\
99,7 \%\end{array}$ \\
\hline
\end{tabular}

mit je $20 \mu \mathrm{l}$ einer Kupfersulfatlösung ( $400 \mathrm{mg} / \mathrm{l}$ ) versetzt. Aus diesen Proben wurden jeweils Doppelbestimmungen, insgesamt 30 Analysen, durchgeführt. Legt man den gemessenen Kupfergehalt der wäßrigen Lösung zugrunde, so ergibt sich bei ciner 30 fachen Bestimmung eine mittlere Wiederfindung von $99,7 \%$. Gleichzeitig kann aus 'Tabclle 1 eine Information übcr die Wicderholbarkeit ("Präzision in der Serie") entnommen werden. Diese liegt mit einem Variationskoeffizicnten von $2,8 \%$ in eincm für cinc Spurenanalyse akzeptablen Bercich.

\section{Präzision und Richtigkcitder Simultanmethode} (Tab. 2-4)

Uber einen Zeitraum von etwa 2 Monaten wurde mit der beschricbenen Simultanmethode von verschicdenen Untersuchern und unter Verwendung jeweils neu angesetzter Reagenzien und Eichlösungen der Gehalt an Kupfer und Eisen in pool-Seren bestimmt. Von dieser Versuchsanordnung erwarteten wir uns Aufschluß über dic Präzision, mit der dic beiden Spurenelemente unter den Bedingungen eines Routinelabors analysiert werden können. Es wurden je $120-150 \mathrm{ml}$ pool-Serum mit niedrigem, normalem und hohem Gehalt an Kupfer bzw. Eisen hergestellt und in Portionen zu je $6 \mathrm{ml}$ bei $-15^{\circ}$ cingefroren. Von diesen 3 pool-Seren wurden über 2 Monate jeweils 35-40 Bestimmungen durchgeführt und die Ergebnisse statistisch bearbeitct (s. Tab. 2). Es zeigte sich im mittleren und hohen Bereich eine deutliche Úberlegenheit der Kupfermethode, dic Variationskocffizienten von nur 5-6\% aufwies, im Gegensatz zur Eisenbestimmung, die unter den gleichen Bedingungen bei 9-10\% Streuung lag. Im niedrigen Bereich war der VK für beide Methoden gleich groß.

Die Riclstigkeit der mit unscrer Methode ermittelten Werte für Kupfer prüften wir durch Vergleichsmessungen mit der Atomabsorptionsmethode ${ }^{1}$ ). Für diese Ver-

1) Herrn Dr. PAsciten, Physiol. Institut der Universität Göttingen sei auch an dicser Stellc für dic Unterstützung bei der Durchführung dieser Vergleichsbestimmungen herzlich gedankt.

Tab. 2

Untersuchungen zur Prözision der Simultanbestimmung von Kupfer und Eisen ain AutoAnalyzer. Messungen über 2-3 Monate im Rahmen der täglich anfallenden Kupfer-Eisen-Bestimnungen

\begin{tabular}{|c|c|c|c|c|c|c|}
\hline & \multicolumn{2}{|c|}{$\begin{array}{c}\text { pool-Serum } \\
\text { "niedrig" }\end{array}$} & \multicolumn{2}{|c|}{$\begin{array}{l}\text { pool-Serum } \\
\text { "mittel" }\end{array}$} & \multicolumn{2}{|c|}{$\begin{array}{c}\text { pool-Serum } \\
\text { "hoch" }\end{array}$} \\
\hline & $\mathrm{Cu}$ & $\mathrm{Fe}$ & $\mathrm{Cu}$ & $\mathrm{Fe}$ & $\mathrm{Cu}$ & $\mathrm{Fe}$ \\
\hline 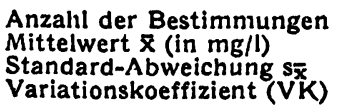 & $\begin{array}{l}37 \\
0,55 \\
0,051 \\
9,3 \%\end{array}$ & $\begin{array}{c}34 \\
0,33 \\
0,034 \\
10,1 \%\end{array}$ & $\begin{array}{l}35 \\
1,46 \\
0,071 \\
4,9 \%\end{array}$ & $\begin{array}{l}34 \\
0,91 \\
0,089 \\
9,7 \%\end{array}$ & $\begin{array}{l}35 \\
2,55 \\
0,014 \\
5,7 \%\end{array}$ & $\begin{array}{l}33 \\
0,81 \\
0,081 \\
10,0 \%\end{array}$ \\
\hline
\end{tabular}

Tab. 3

Untersuchungen zur Richtigkeit der Kupferbestimmung an AutoAnalyzer ( $\left.\mathrm{Cu}_{3}\right)$ mit 3 verschiedenen pool-Seren. Die gleichen Seren wurden nach entsprechender Verdünnung an einem Atomabsorptionsphotometer (Perkin-Eimer 303) auf ihren Kupfergehalt untersucht (Cu $\mathrm{A}$ )

\begin{tabular}{|c|c|c|c|c|c|c|}
\hline & \multicolumn{2}{|c|}{$\begin{array}{l}\text { pool-Serum } \\
\text { "niedrig" }\end{array}$} & \multicolumn{2}{|c|}{$\begin{array}{l}\text { pool-Serum } \\
\text { "mittel“" }\end{array}$} & \multicolumn{2}{|c|}{$\begin{array}{l}\text { pool-Serum } \\
\text { hoch" }\end{array}$} \\
\hline & $\mathrm{Cu}_{\mathrm{A}}$ & $C_{11] 3}$ & $\mathrm{Cu}_{\mathrm{A}}$ & $\mathrm{Cu}_{\mathbf{B}}$ & $\mathrm{Cu}_{\boldsymbol{\Lambda}}$ & $\mathrm{Cu}_{\mathbf{B}}$ \\
\hline $\begin{array}{l}\text { Anzahl der Bestimmungen } \\
\text { Mittelwert } \mathrm{X} \text { (in mg/l) } \\
\text { Standard-Abweichung } \mathbf{s} \\
\text { Variations-Koeffizient VK }\end{array}$ & $\begin{array}{l}21 \\
0,67 \\
0,21 \\
32,3 \%\end{array}$ & $\begin{array}{l}37 \\
0,55 \\
0,051 \\
9,3 \%\end{array}$ & $\begin{array}{l}21 \\
1,55 \\
0,016 \\
10,5 \%\end{array}$ & $\begin{array}{l}35 \\
1,46 \\
0,071 \\
4,9 \%\end{array}$ & $\begin{array}{l}11 \\
2,52 \\
0,054 \\
2,1 \%\end{array}$ & $\begin{array}{l}35 \\
2,55 \\
0,014 \\
5,7 \%\end{array}$ \\
\hline Abweichung $\left(\mathrm{Cu}_{\mathbf{A}}-\mathrm{Cu}_{13}\right)$ & \multicolumn{2}{|c|}{$+0,12 \mathrm{mg} / \mathrm{l}$} & \multicolumn{2}{|c|}{$+0,00 \mathrm{mg} / \mathrm{l}$} & \multicolumn{2}{|c|}{$-0,03 \mathrm{lng} / \mathrm{l}$} \\
\hline
\end{tabular}


Tab. 4

Vergleich der Ergebnisse der Simultanmethode am AutoAnalyzer mit den empfohlenen Werten eines Kontrollserums (Seronorm)

\begin{tabular}{|c|c|c|}
\hline \multirow[b]{2}{*}{ Empfohlener Wert (Bereich) } & \multicolumn{2}{|c|}{$\begin{array}{c}\text { Kontroll-Serum } \\
\text { Kupfer }\end{array}$} \\
\hline & $\begin{array}{l}1,01 \mathrm{mg} / 1 \\
(0,91-1,09)\end{array}$ & $1,43 \mathrm{mg} / \mathrm{l}$ \\
\hline $\begin{array}{l}\text { Anzahl der Bestimmungen } \\
\text { Mittelwert } \bar{x} \text { (in mg/l) } \\
\text { Standardabweichung } s \bar{x} \\
\text { Variationskoeffizient VKK } \\
\text { Mittelwert } \bar{x} \text { - empfohlener Wert } \\
\text { Abweichung in \% }\end{array}$ & $\begin{array}{l}41 \\
1,02 \\
0,061 \\
6,0 \% \\
+0,013 \mathrm{mg} / 1 \\
+1,3 \%\end{array}$ & $\begin{array}{l}40 \\
1,45 \\
0,113 \\
7,8 \% \\
+0,022 \mathrm{mg} / 1 \\
+1,4 \%\end{array}$ \\
\hline
\end{tabular}

suchsserie zogen wir die Ergebnisse der 3 pool-Seren heran und stellten sie den Werten der Atomabsorption (AA-Spektrophotometer 303 der Firma PerkinElmer) gegenüber (s. Tab. 3). Es fällt auf, daß im niedrigen und mittleren Bereich mit der Atomabsorption deutlich höhere Werte gemessen werden als mit der kolorimetrischen Methode. Im hohen Bereich stimmen die Werte praktisch überein. Hier zeigt die Atomabsorption auch den kleinsten Variationskoeffizienten, der im mittleren und niedrigen Konzentrationsbereich jedoch beträchtlich ist (VK 32,3\%!).

Weiteren Aufschluß über die Richtigkeit der Analysenergebnisse von Kupfer und Eisen ergaben die in jeder Versuchsserie ermittelten Werte eines käuflichen Kontrollserums (Seronorm Nygaard, Firma Molter, Heidelberg). Die statistische Bearbeitung von insgesamt

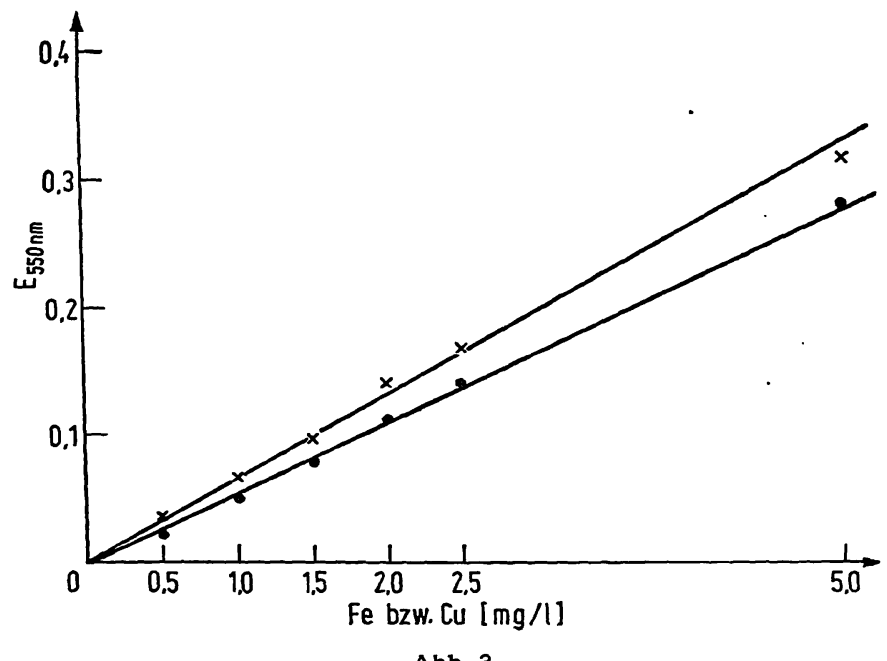

Abb. 3

Eichkurven für die Kupfer- und Eisenbestimmung am Auto-Analyzer (Fließschema s. Abb. 1) nach Umrechnung der Transmissionswerte in die entsprechenden Extinktionen. Für beide Methoden liegt im Bereich von $0,5-5,0 \mathrm{mg} / 1$ Linearität vor $\dot{\mathrm{x}}=\mathrm{K}=$ Kisenstandards

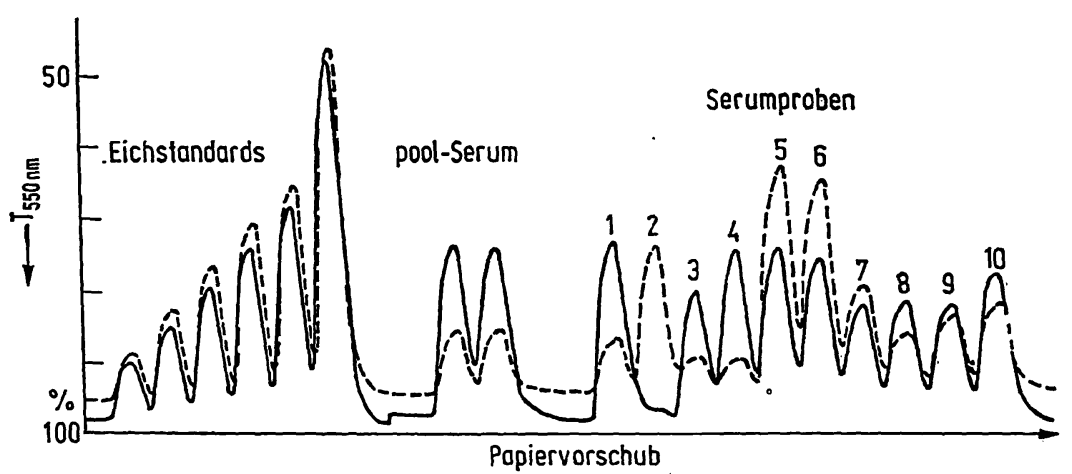

40 Wertepaaren lieferten die in Tabelle 4 zusammengestellten Resultate. Bei etwa gleich guter Präzision wie in Tabelle 3 ergab sich für beide Parameter eine ausgezeichnete Richtigkeit: Unsere gemessenen Werte differierten im Mittel um nur 0,013 bzw. $0,022 \mathrm{mg} / \mathrm{l}$ von den „empfohlenen Werten", die prozentuale Abweichung betrug $1,3 \%$ bzw. $1,4 \%$.

\section{Diskussion}

Für die Bestimmung des Eisens am Auto-Analyzer liegen bereits eine Reihe brauchbarer Arbeitsvorschriften $(9,10,11)$ vor. Daher richteten wir unser Hauptaugenmerk auf die Möglichkeiten der Kupferbestimmung im kolorimetrischen Test. Als farbgebende Komplexbildner in wäßriger Lösung wurden folgende Verbindungen in Betracht geżogen (die jeweiligen molaren Extinktionswerte in Klammern):

Diäthyl-Dithiocarbamat $\left(8 \times 10^{3}\right)$, Neocuproin $(7,6 \times$ $\left.10^{3}\right)$, Bathocuproin $\left(12 \times 10^{3}\right)$, Cuprizon $\left(14 \times 10^{3}\right)$, Oxalyldihydrazid $\left(22 \times 10^{3}\right)$, Dithizon $\left(24 \times 10^{3}\right)$ und Diphenylcarbazid $\left(158 \times 10^{3}\right)$.

Wegen seiner hohen molaren Extinktion scheint das Diphenylcarbazid für die Kupferbestimmung im Mikrogrammbereich in erster Linie in Frage zu kommen. Auf die Schwierigkeiten der Kupferbestimmung mit Diphenylcarbazid in wäßriger Lösung hatten bereits Stoner und Dasler (12) hingewiesen. Obwohl sich einige dieser Schwierigkeiten, z. B. exakte Einhaltung der Reaktionszeit, Leerwertkorrektur, kontinuierliche $\mathrm{pH}-$ Kontrolle am Auto-Analyzer beherrschen lassen, gelang es uns nicht, eine störungsfreie, für Routinezwiecke geeignete Methode unter Verwendung von Diphenylcarbazid $z u$ entwickeln. Eine Extraktion des Kupfer-Komplexes in organische Phase, wie von den genannten Autoren (12), sowie von Mrkac-Devic (13) vorgeschlagen, schien uns für den Auto-Analyzer zu aufwendig zu sein.

Aufgrund des höheren molaren Extinktionskoeffizienten zogen wir als nächste Substanz das Oxalyldihydrazid in Betracht, und nicht das bei den meisten manuellen Methoden verwendete Bathocuproin. [Übersicht s. bei BorChardt und ButLer (14)]. Dabei konnten wir uns auf die Mitteilungen von Stark und Dawson (15), Bèale und Croft (16), sowie hinsichtlich des AutoAnalyzers auf eine Arbeit von Summers (8) stützen. Bei dem dort angegebenen Fließschema kommt allerdings
Abb: 4

Kurvenbild der Simultanbestimmung für Kupfer (ausgezogene Kurven) und Eisen (gestrichelte Kurven) in wäßr. Eichstandards $(0,5$ bis $5,0 \mathrm{mg} / \mathrm{l})$, zwei Proben eines pool-Serums uńd 10 Serumproben. - Serum Nr. 2 stammt von einem WILSON-Patienten mit extrem niedrigem Serumkupfer 
eine Dialyse unter erhöhtem Druck zur Anwendung, was nach unseren Erfahrungen die Betriebssicherheit des Systems erheblich verschlechtert. Außerdem erschien uns der ,aktuelle Probenaussto $B^{\text {" mit }}$ meniger als 10 Bestimmungen/Std. - bedingt durch 2 StandardEichkurven und je 1 Leergefäß bei einer Frequenz des Probennehmers von 20/Std. - als zu gering.

Es zeigte sich jedoch in unseren Untersuchungen, daß man mit einer genügend großen Probenmenge und durch Wahl geeigneter Reaktionsbedingungen mit einer normalen Einfachdialyse gut ablesbare Standard- bzw. Analysenwerte erhält. Die Eichkurve verlief in dem klinisch relevanten Bereich von $0,5-5 \mathrm{mg} / \mathrm{l}$ linear (Abb. 3), der Verschleppungsfehler von hohen zu niedrigen Kupferkonzentrationen lag unterhalb der Nachweisbarkeitsgrenze.

Die weitere Prüfung der beschriebenen Methode zur Kupferbestimmung verlief zufriedenstellend: Spezifität und Empfindlichkeit waren für eine Analyse im Serum genügend, die Wiederfindungstate zugesetzter Kupfer- standards lag überraschend hoch und die Wiederholbarkeit in der Serie war für eine Spurenanalyse mit 3-4\% Streuung akzeptabel. Verständlicherweise fanden wir den Variationskoeffizienten für die Präzision bei einer Untersuchung über 2-3 Monate in einem höheren Bereich (5-6\%), wobei für niedrige Kupferkonzentrationen wegen der schwierigeren Ablesung kleiner "peaks" eine deutlich höhere Standardabweichung resultiert (s. Tab. 2). Dennoch glauben wir, die beschriebene Auto-Analyzer-Methode für Kupfer aufgrund der Ergebnisse der Richtigkeitsprüfung (s. Tab. 3 und 4) für das klinisch-chemische Labor ohne Einschränkung empfehlen zu können.

Die entsprechenden Werte der Präzision für die Eisenbestimmung in Tabelle 2 können hingegen noch nicht als befriedigend angesehen werden. Es wäre zu prüfen, ob mit dem von Young und Hicks (11) oder ScHMrdi und Mitarbeitern (11) angegebenen Verfahren bei Koppelung mit der Kupferbestimmung bessere Resultate für die Präzision erreicht werden.

\section{Literatur}

1. LANGe, J., Dtsch. med. Wschr. 90, 1406 (1965). - 2. FintelMANN, V., Dtsch. med. Wschr. 94, 1244 (1969). - 3. HollaranN, S., in: Schoen, R. und S. SüDhoF, Biochemische Befunde in der Differentialdiagnose innerer Krankheiten, 2. Auflage, ThiemeVerlag, Stuttgart (1965). - 4. HeEsEN, H., Laborbefunde in der Differentialdiagnostik innerer Krankheiten, Thieme-Verlag, Stuttgart (1970). - 5. Beutler, E., V. F. Fairbanks und J. L. Fahey, Clinical Disorders of Iron Metabolism, Grune and StrattonVerlag, New York (1963). - 6. StAMM, D. und H. BütTNER, diese Z. 7, 393 (1969). - 7. Stamm, D., persönl. Mitteilung (Ringversuch 1969). - 8. Summers, R. M., Analytic. Chem. 32,
1903 (1960). - 9. ZaK, B. und E. Epstein, Clin. Chem. (New York) 11, 641 (1965). - 10. Young, D. S. und J. M. Hicks, J. Clin. Path. London 18, 98 (1965). - 11. Schmrdt, R., W. Wers, V. KLINGMÜLLER und HJ. StAudinger, diese Z. 5, 304 (1967). 12. Stoner, R. E. und W. Daster, Clin. Chem. (New York) 10, 845 (1964). - 13. Mrkac-Devic, D., Clin. Chim. Acta, Amsterdam 26, 127 (1969). - 14. Borchardt, LE Roy, G. und J. P. Butler, Analytic. Chem. 29, 414 (1957). - 15. Stark, G. R. und C. R. Dawson, Analytic. Chem. 30, 191 (1958). - 16. Beale, R. N. und D. Croft, J. Clin. Path. London 17, 260 (1964). 